\title{
Diagnostic value of peripheral lymph node biopsy in sarcoidosis: A report of 67 cases
}

\author{
Halil Yanardag $M D^{1}$, Metin Caner $M D^{2}$, Irfan Papila $M D^{3}$, Sedat Uygun $M D^{1}$, \\ Sabriye Demirci $M D^{1}$, Tuncer Karayel MD ${ }^{1}$
}

H Yanardag, M Caner, I Papila, S Uygun, S Demirci, T Karayel. Diagnostic value of peripheral lymph node biopsy in sarcoidosis: A report of 67 cases. Can Respir J 2007;14(4):209-211.

A peripheral lymph node (PLN) $1 \mathrm{~cm}$ or greater was found in 79 of 546 sarcoidosis patients (14.5\%) between 1972 and 2005. Seventytwo of the 79 sarcoidosis patients had a lymph node biopsy performed. Sixty-seven of these biopsy specimens were histologically diagnosed as sarcoidosis, whereas five patients had a reactive adenopathy. For patients with histological diagnosis of sarcoidosis, localizations of the biopsies were as follows: cervical $(n=21)$, supraclavicular $(n=20)$, inguinal $(n=11)$, axillary $(n=8)$, epitrochlear $(n=5)$ and submandibular $(n=2)$. At the time of biopsy, 12 patients had stage 0 disease, 37 patients had stage I disease, 14 patients had stage II disease and four patients had stage III disease. Skin involvement $(16.4 \%)$ was the most frequently observed type of organ involvement in patients who had enlarged PLNs due to sarcoidosis. In the presence of an enlarged PLN in sarcoidosis, biopsy had a greater diagnostic value compared with other methods, as well as having a relatively low cost (approximately US\$120) in Turkey. No procedure-related complications were observed. In conclusion, it is recommended that PLNs be thoroughly examined when sarcoidosis is suspected. If an enlarged PLN is found, biopsy should be routinely performed because it is an easy, convenient and practical method, with a low complication risk and a high sensitivity.

\author{
La valeur diagnostique d'une biopsie de \\ ganglion lymphatique périphérique en cas de \\ sarcoïdose : Rapport de 67 cas
}

Key Words: Peripheral lymph node; Pulmonary sarcoidosis; Sarcoidosis; Transbronchial lung biopsy

Garcoidosis is a multisystem disease of unknown etiology $\checkmark$ characterized by the formation of noncaseating granulomas in the affected organs. For a typical case, diagnosis of sarcoidosis is made by a combination of clinical, radiographic and histological findings. In a young adult who has constitutional complaints, respiratory symptoms, erythema nodosum, blurred vision and bilateral hilar lymphadenopathy, the diagnosis is easy. Commonly, however, the findings are more subtle. Furthermore, sarcoidosis can occur in almost any place in the body; like tuberculosis, it can be confused with many other disorders (1-3). Because the prevalence of tuberculosis is high in Turkey (40 cases per 100,000 people), differential diagnosis of sarcoidosis can be difficult.

In sarcoidosis, pulmonary involvement can be observed in $90 \%$ of the patients and is often bilateral. The lesions may be misdiagnosed as malignant metastases. An intrathoracic or peripheral lymphadenopathy is a very common finding. In more than $90 \%$ of the cases, hilar or paratracheal lymph nodes are enlarged. Peripheral lymph nodes (PLNs), if enlarged, are
On a observé un ganglion lymphatique périphérique (GLP) d'au moins $1 \mathrm{~cm}$ chez 79 des 546 patients atteints de sarcoïdose (14,5\%) entre 1972 et 2005. Soixante-douze de ces 79 patients ont subi une biopsie du ganglion lymphatique. Soixante-sept de ces échantillons de biopsie ont été histologiquement diagnostiqués comme des sarcoïdoses, tandis que cinq d'entre eux étaient des adénopathies réactives. Chez les patients ayant reçu un diagnostic histologique de sarcoïdose, le foyer des biopsies s'établissait comme suit : cervical $(n=21)$, supraclaviculaire $(n=20)$, inguinal $(n=11)$, axillaire $(n=8)$, épitrochléaire $(n=5)$ et sous-maxillaire $(\mathrm{n}=2)$. Au moment de la biopsie, 12 patients étaient atteints d'une maladie de stade 0,37 , d'une maladie de stade 1,14 , d'une maladie de stade 2 et quatre, d'une maladie de stade 3. Les lésions cutanées (16,4\%) représentaient le type d'atteinte organique le plus fréquent chez les patients présentant un GLP hypertrophié causé par une sarcoïdose. En présence d'un tel ganglion, la biopsie avait une meilleure valeur diagnostique que d'autres méthodes, sans compter son coût relativement peu élevé (environ 120 \$ US) en Turquie. On n'a observé aucune complication reliée aux interventions. Pour conclure, nous recommandons d'examiner le GLP sous tous les angles en cas de présomption de sarcoïdose. En présence de GLP hypertrophié, la biopsie devrait être systématique parce que c'est une méthode facile, commode et pratique, à la sensibilité élevée et au faible risque de complication.

${ }^{1}$ Department of Lung Diseases; ${ }^{2}$ Department of Surgery; ${ }^{3}$ Department of Otolaryngology, Cerrahpaşa Medical Faculty, University of Istanbul, Istanbul, Turkey

Correspondence: Dr Halil Yanardağ, İstanbul Üniversitesi, Cerrahpaşa Tıp Fakültesi, İç Hastalıkları Ana Bilim Dalı, Akciğer Hastalıkları

Bölümü, Aksaray, Istanbul, Turkey. E-mail halilyanardag@yahoo.com 


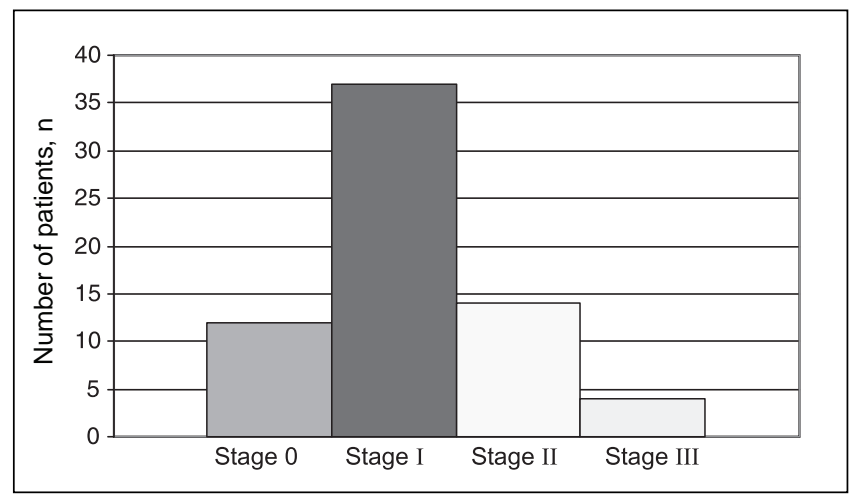

Figure 1) Distribution of disease stages among patients diagnosed with sarcoidosis $(n=67)$ by lymph node biopsy

\section{TABLE 1}

Regional distribution of lymph nodes

\begin{tabular}{lcc}
\hline & Frequency & Percentage \\
\hline Cervical & 21 & 31.3 \\
Supraclavicular & 20 & 29.9 \\
Inguinal & 11 & 16.4 \\
Axillary & 8 & 11.9 \\
Epitrochlear & 5 & 7.5 \\
Submandibular & 2 & 3.0 \\
Total & 67 & 100.0 \\
\hline
\end{tabular}

Pneumology at the University of Istanbul (Istanbul, Turkey), were retrospectively examined.

Medical records were used to obtain data regarding the patients' age, sex and disease stage. Disease stage was determined by using chest $\mathrm{x}$-ray and biopsy findings. All study subjects met clinical and/or radiological features for sarcoidosis; diagnosis was also supported by histological evidence of noncaseating granulomas. Although the histology of one lymph node cannot, in itself, establish the diagnosis for sarcoidosis, which is a generalized disease, detailed histological study of biopsy tissue makes an important and often essential contribution. In many instances, a complete lack of necrosis, an intact reticulin pattern and a failure to demonstrate infective agents permit an unequivocal statement of compatibility with the diagnosis of sarcoidosis; however, a compatible clinical picture, and an absence of evidence for known causes of local granulomatous reactions or of other generalized granulomatous diseases, are required for definitive diagnosis (7).

Patients who had clinical and radiological features of sarcoidosis were excluded if there was no histological confirmation.

Chest $x$-ray findings were classified according to American Thoracic Society/European Respiratory Society/World Association of Sarcoidosis and other Granulomatous Disorders statement on sarcoidosis (8). According to this statement, there are five roentgenographic stages of intrathoracic changes. Stage 0 means there are no visible intrathoracic findings. Bilateral hilar lymphadenopathy, which may be accompanied by paratracheal adenopathy, is classified as stage I. In this stage, although lung fields are clear of infiltrates, parenchymal granulomas are often found in the lung tissue biopsies. Stage II encompases a bilateral hilar adenopathy accompanied by parenchymal infiltration, and stage III means there is a parenchymal infiltration without hilar adenopathy. Stage IV consists of an advanced pulmonary fibrosis
TABLE 2

Organ involvement of patients $(n=67)$

\begin{tabular}{lcc}
\hline & Frequency & Percentage \\
\hline Skin & 11 & 16.4 \\
Eyes & 4 & 6.0 \\
Liver & 4 & 6.0 \\
Spleen & 3 & 4.5 \\
Parotid gland & 2 & 3.0 \\
Bone & 1 & 1.5 \\
Central nervous system & 1 & 1.5 \\
Tonsil & 1 & 1.5 \\
Total & 27 & 40.4 \\
\hline
\end{tabular}

with evidence of honeycombing, hilar retraction, bullae, cysts and emphysema (6-8).

An enlarged lymph node $1 \mathrm{~cm}$ or greater was found in 79 patients (14.5\%); a PLN biopsy was performed in 72 of the 79 patients, while seven patients did not undergo biopsy owing to lack of consent. Histological findings consistent with sarcoidosis were obtained in 67 patients (93\%).

The $\chi^{2}$ test (Fisher's exact test) and the Student's $t$ test were used for statistical analysis.

\section{RESULTS}

Of the 67 patients diagnosed with sarcoidosis, mean ( \pm SD) age was $37.91 \pm 11.79$ years (ranging from 13 to 64 years of age). Forty-two patients $(62.7 \%)$ were female and 25 patients $(37.3 \%)$ were male. The distribution of disease stages at the time of biopsy is shown in Figure 1. Among the patients diagnosed with sarcoidosis, 12 patients had stage 0 disease, 37 patients had stage I disease, 14 patients had stage II disease and four patients had stage III disease.

The regional distribution of lymph nodes is shown in Table 1. Sarcoidosis was most frequently found at cervical $(31.3 \%)$ and supraclavicular $(29.9 \%)$ regions, followed by inguinal regions $(16.4 \%)$.

In 27 of the 67 cases $(40.4 \%)$, other organs were also involved. The distribution of organ involvement is shown in Table 2. The most frequently involved organ was the skin (16.4\%). Of the 11 patients who had skin involvment, 10 had a skin biopsy performed and among these, eight were found to have sarcoidosis. Lymph node biopsy was also performed to clarify the diagnosis and to determine the absolute cause of adenopathy. The purified protein derivative (PPD) test was negative for $80.6 \%$ of the patients and positive for $19.4 \%$. Female patients had a significantly lower positive rate $(11.9 \%$, five of 42$)$ in the PPD test compared with the rate in male patients (32.0\%, eight of $25, \mathrm{P}<0.05)$, which was probably due to the higher exposure rate of males to Mycobacterium tuberculosis.

The diagnosis of sarcoidosis was most frequently established by bronchoscopy and transbronchial lung biopsy $(41.9 \%)$, followed by clinical and radiological evaluations (24.8\%), and lymph node biopsy (12.3\%). Clinical and radiological diagnosis was defined as the presence of clinical and radiological findings consistent with sarcoidosis, the exclusion of other conditions and at least one year of follow-up to exclude all other possibilities other than sarcoidosis. Of the 67 patients, eight skin biopsies and 21 lymph node biopsies were directly analyzed and cultured for tuberculosis, and in all cases the PPD test was negative. 


\section{DISCUSSION}

Although different studies report variable incidences for PLN involvement in sarcoidosis, it is reported that nearly $2 \%$ to $25 \%$ of the cases show PLN involvement and that histological prevalence varies from $7.7 \%$ to $100 \%(3,9-11)$. Aytemur et al (12) found peripheral lymphadenopathy in eight of 77 sarcoidosis cases $(10.4 \%)$, and supraclavicular lymph node biopsy was performed in three of the 77 cases (3.9\%) for diagnosis. The lymph nodes are the preferred sites for biopsy specimens. If no specific lesion is identified, bronchoscopic transbronchial lung biopsy, mediastinal lymph node biopsy, liver biopsy or parotid biopsy is recommended, depending on the clinical findings, nonspecific lesions and the results of radiological examination. In a long-term study (10) of patients with sarcoidosis, $11.7 \%$ presented with PLN involvement.

At the time of the 3rd International Conference on Sarcoidosis, two studies $(13,14)$ reported a high rate of positive PLN biopsies in patients who had histologically proven sarcoidosis. Israel and Sones (13) obtained a diagnostic biopsy in 157 of 329 patients (47\%) who had histologically proven sarcoidosis: 84 biopsies were from cervical lymph nodes, 51 biopsies were from axillary lymph nodes and 22 diagnostic biopsies were from inguinal lymph nodes (13). Löfgren and Snellman (14) obtained a diagnostic PLN biopsy in 173 patients (66\%) of 261 similar cases. In 1985, Scadding and Mitchell (11) obtained a diagnostic biopsy from PLNs in 66 of 275 patients (24\%). In 1998, Wirnsberger et al (15) presented a study on procedures for the assessment of sarcoidosis in 1045 patients. Diagnosis was established by mediastinoscopy in 200 patients, by thoracoscopy in 272 patients and by bronchoscopy in 573 patients; however, PLN biopsy was not obtained in any of the patients. A major reason for the shift from PLN biopsy to transbronchial biopsy is so that bronchoaveolar lavage fluid and the transbronchial biopsy specimen can be studied at the same time. However, recent international guidelines for sarcoidosis still suggest performing a PLN biopsy when such an approach is easily pursuable (16-19).

\section{REFERENCES}

1. Newman LS, Rose CS, Maier LA. Sarcoidosis. New Engl J Med 1997;336:1226-34. (Erratum in 1997;337:139).

2. James DG. Lymphoreticular involvement. In: James DG, ed. Sarcoidosis and Other Granulomatous Disorders. New York: Marcel Dekker, 1994:345-7.

3. Stirling RG, Cullinan P, Du Bois RM. Sarcoidosis. In: Schwarz M, King T, eds. Intestinal Lung Disease. Hamilton: BC Dekker Inc, 1988:279-323.

4. Muller-Quernheim J. Sarcoidosis: Immunopathogenic concepts and their clinical application. Eur Respir J 1998;12:716-38.

5. Torrington KG, Shorr AF, Parker JW. Endobronchial disease and racial differences in pulmonary sarcoidosis. Chest 1997;111:619-22.

6. DeRemee RA. The roentgenographic staging of sarcoidosis.

Historic and contemporary perspectives. Chest 1983;83:128-33.

7. Mitchell DN, Scadding JG, Heard BE, Hinson KF. Sarcoidosis: Histopathological definition and clinical diagnosis. J Clin Pathol 1977;30:395-408.

8. Hunninghake GW, Costabel U, Ando M, et al. ATS/ERS/WAGOS statement on sarcoidosis. Sarcoidosis Vasc Diffuse Lung Dis 1999;16:149-73.

9. Rizatto G, Montemurro L. The clinical spectrum of the sarcoid peripheral lymph node. Sarcoidosis Vasc Diffuse Lung Dis 2000;17:71-80.

10. Scadding JG, Mitchell DN. Superficial lymphadenopathy. In: Scadding JG, Mitchell DN, eds. Sarcoidosis. London: Chapman and Hall, 1985:252-9.
The cost of fine-needle aspiration biopsy has been assessed at $12.5 \%$ to $50 \%$ of the cost of tissue biopsy (18). Fine-needle aspiration biopsy appears to be underused in the diagnosis of sarcoidosis. When used in conjunction with radiological and laboratory data, it may be a reliable and cost-effective method of diagnosis of suspicious lesions, especially in patients with an established diagnosis of sarcoidosis (18).

Computed tomography, magnetic resonance imaging and ultrasound have a $20 \%$ to $28 \%$ higher sensitivity for the detection of peripheral lymphadenopathy than clinical assessment (20). Therefore, ultrasound-guided lymph node examination may be of further help in the diagnosis of sarcoidosis. We believe that this matter should be further investigated.

In our study, 546 sarcoidosis cases, followed at Cerrahpaşa Medical School, Istanbul University (Istanbul, Turkey), between 1972 and 2005 were examined. At least one enlarged PLN (1 $\mathrm{cm}$ or greater) was found in 79 of the 546 patients. A PLN biopsy was performed on 72 of the 79 cases who had enlarged lymph nodes. A typical noncaseating granuloma due to sarcoidosis was found in 67 cases (93\%). A study by Gurkan et al (19) found 8.9\% of patients with typical noncaseating granuloma in 1327 patients (19).

Sarcoid-type granuloma in a PLN may be due to a reaction from a nearby malignant tumour, or from tuberculosis or other inflammatory disease. In our study, noncaseating granulomas were found in all biopsies, and acid-fast (Ziehl-Neelsen) and fungal stains were all negative. In addition, all cases were followed for at least one year and all other conditions were excluded.

No biopsy-related complication was observed. Diagnosis of sarcoidosis was established by PLN biopsy in 67 of 546 cases (12.3\%). In the presence of an enlarged PLN in sarcoidosis, biopsy provided a high diagnostic value (93\%) compared with that of other methods, without giving rise to any complications. Therefore, we recommend that PLNs, particularly cervical, supraclavicular, axillary, inguinal, submandibular and epitrochlear lymph nodes, should be thoroughly examined when sarcoidosis is suspected. For the detection of lymph nodes, ultrasonography should be used when necessary.

11. Scadding JG, Mitchell DN. Prevalence, incidence and modes of presentation in sarcoidosis. In: Scadding JG, Mitchell DN, eds. Sarcoidosis. London: Chapman and Hall 1985:43-71.

12. Aytemur ZA, Erdinc M, Erdinc E, Ates H, Akyurekli O. [Clinical features and diagnostic approach to sarcoidosis according to stages.] Tuberk Toraks 2003;51:11-6.

13. Israel HL, Sones M. Selection of biopsy procedures for diagnosis of sarcoidosis. Acta Med Scand Suppl 1964:425:222-4.

14. Lofgren S, Snellman B. Principles and procedures for obtaining biopsies in sarcoidosis. Acta Med Scand Suppl 1964;425:225-7.

15. Wirnsberger RM, de Vries J, Wouters EF, Drent M. Clinical presentation of sarcoidosis in The Netherlands an epidemiological study. Neth J Med 1998;53:53-60.

16. Handa R, Aggarwal P, Wali JP, Wig N, Dinda AK, Biswas A. Sarcoidosis presenting with peripheral lymphadenopathy. Sarcoidosis Vasc Diffuse Lung Dis 1998;15:192.

17. Mana J, Gomez-Vaquero C, Montero A, et al. Lofgren's syndrome revisited: A study of 186 patients. Am J Med 1999;107:240-5.

18. Tambouret R, Geisinger KR, Powers CN, et al. The clinical application and cost analysis of fine-needle aspiration biopsy in the diagnosis of mass lesions in sarcoidosis. Chest 2000;117:1004-11.

19. Gurkan OU, Celik G, Kumbasar O, Kaya A, Alper D. Sarcoidosis in Turkey: 1954-2000. Ann Saudi Med 2004;24:36-9.

20. Van den Brekel MW, Stel HV, Castelijns JA, et al. Cervical lymph node metastasis: Assessment of radiologic criteria. Radiology 1990;177:379-84. 


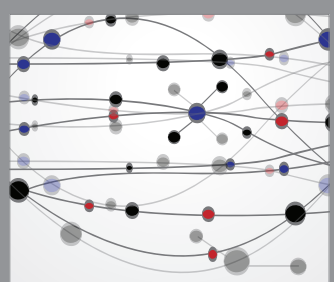

The Scientific World Journal
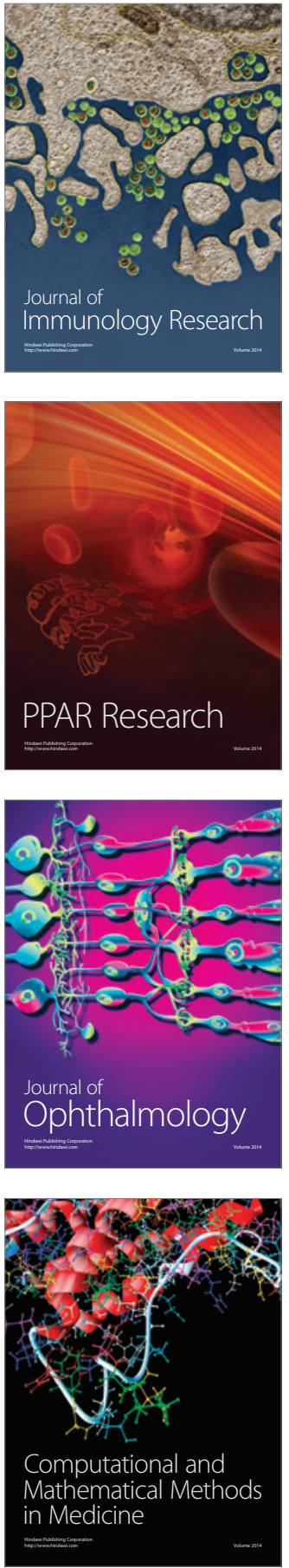

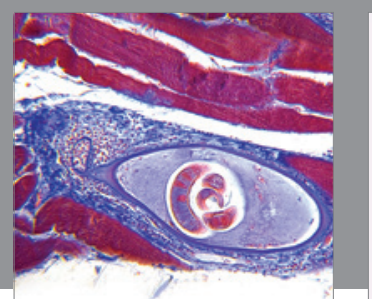

Gastroenterology Research and Practice

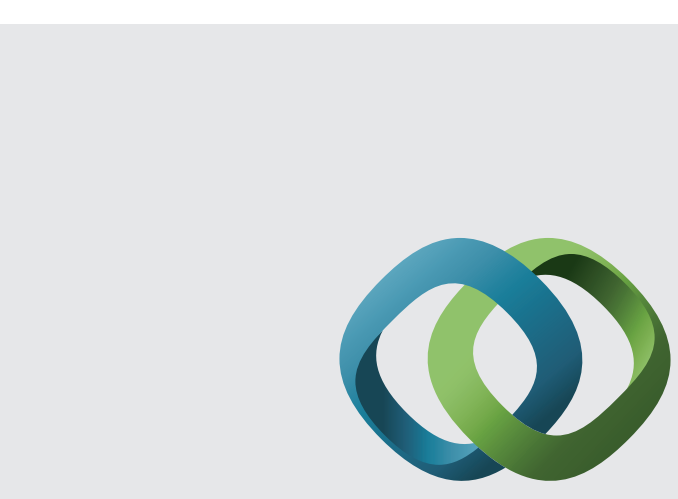

\section{Hindawi}

Submit your manuscripts at

http://www.hindawi.com
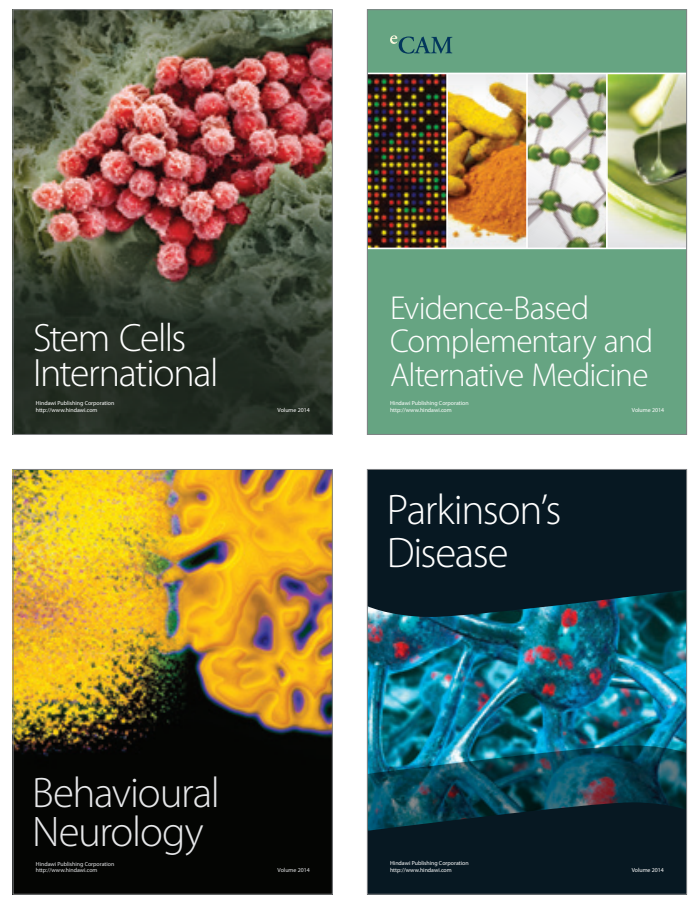
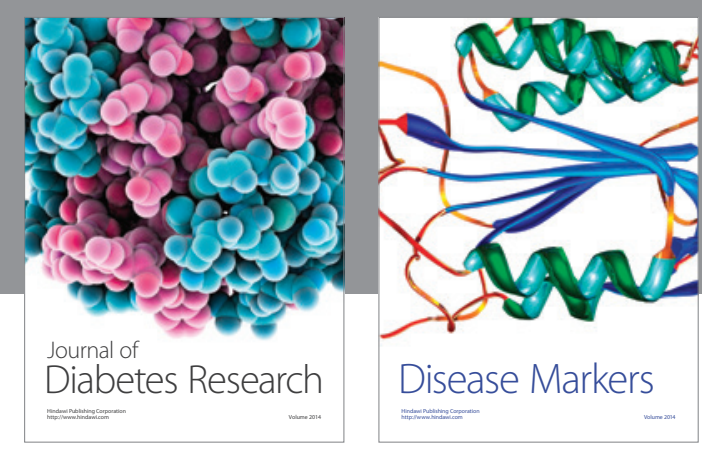

Disease Markers
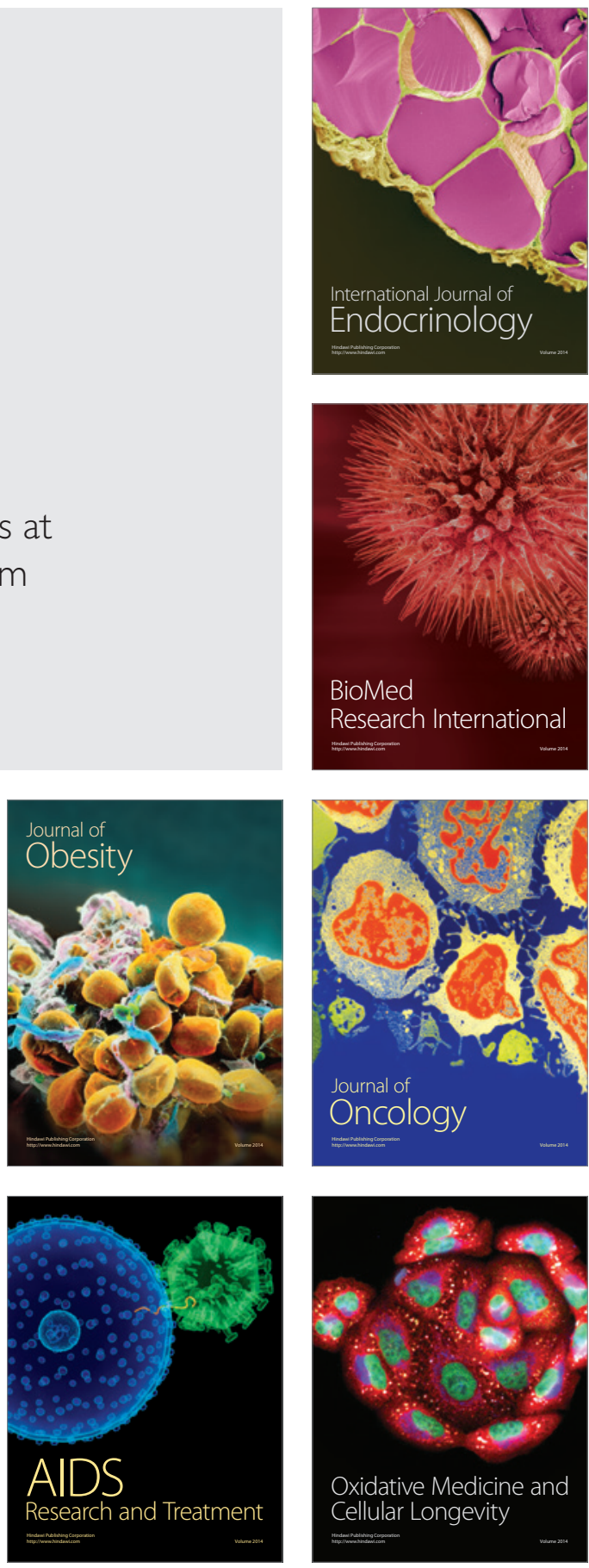